\title{
8
}

\section{The Tangarutu invertebrate fauna}

\author{
Katherine Szabó \\ Centre for Archaeological Science, University of Wollongong; Department of Archaeology and Natural \\ History, The Australian National University, Canberra, Australia, Kat.Szabo1@gmail.com \\ Atholl Anderson \\ Department of Archaeology and Natural History, The Australian National University
}

\section{Introduction}

The island of Rapa presents an interesting lens through which to investigate human decisionmaking and resource-use patterns in a marginal environment. In addition to being small and isolated, Rapa is climatically marginal, being positioned on the southern fringe of the tropical Indo-West Pacific marine province. Most obviously, this geographical situation translates to restricted species diversity, with a great many common tropical taxa not able to survive the conditions. However, as pointed out by Preece (1995:345), it would be a mistake to see the marine fauna of marginal Polynesian islands as simply an impoverished subset of the tropical Indo-West Pacific community. Indeed, Paulay and Spencer (1988, in Irving 1995:321) suggest that there is a belt of islands in the central-eastern Pacific (including Easter Island, the Pitcairn Islands, Kermadecs, Rapa and Lord Howe) that have a littoral fauna specifically adapted to cooler conditions. Such species include a number of endemics, as well as species restricted solely to the islands listed above. The dominant mollusc within the Tangarutu assemblage - Nerita morio - is one such species (see below for discussion).

While this distinctive intermediate fauna may suggest a reasonable degree of faunal stability through time, studies done at other islands within this zone (notably the Pitcairn Group) have demonstrated otherwise. A comparison of Pleistocene subfossil assemblages and extant littoral communities on Henderson Island showed considerable turnover (Paulay and Spencer in Irving 1995:321). Such turnovers can be explained in different ways, including by relatively small population sizes, species existing at the limits of their environmental tolerances, and isolation limiting recruitment of individuals from other islands. While only providing a small slice of Rapa's history, the Tangarutu marine invertebrate assemblage presents an opportunity to assess human subsistence practices in an environment that is therefore not only impoverished, but dynamic in its constituents.

The Tangarutu site is adjacent to Anarua Bay, which contains a variety of littoral invertebratebearing habitats. With tall cliffs at the northern and southern ends, the bay is west-facing and 
thus usually sheltered from the prevailing southeasterlies. The prevailing winter winds in Rapa are westerlies (Irving 1995:321), meaning Anarua Bay would see high wave action for a period each year. Within the bay itself are rocky intertidal platforms, sandy patches and basalt gravel zones, providing a variety of niches for infaunal (within the substrate) and epifaunal (atop the substrate) littoral marine life. The archaeological deposits excavated from Tangarutu contained small but consistent quantities of invertebrate remains, representing a varied mix of mollusc, crustacean and echinoid species. This chapter presents the results of analysis, and considerations of subsistence, palaeoenvironment and gathering strategies.

\section{Methodology}

All shell, crustacean and echinoderm remains from the E1 and E2 squares of Tangarutu were analysed, with all molluscan remains identified to the lowest possible taxonomic level - generally species. Molluscan taxonomy follows Dharma (2005), with up-to-date taxonomy drawn from the OBIS online database (http://clade.ansp.org/obis/). Crustacean remains included crab exoskeleton fragments, as well as 'goose barnacle' (Lepas anatifera) plates. All crab remains were quantified as a single taxonomic category without any attempt at identification, while Lepas anatifera remains were quantified separately. Echinoderms were represented by teeth, spines and test fragments of a single taxon, identified as Diadema cf. setosum (but see discussion of urchin identification below).

Remains were highly fragmented at all levels, although otherwise very well preserved. While both MNI and NISP values, along with weights, were recorded, the NISP values will be reported here. This is not only due to the small sample sizes and consistent levels of breakage across taxa, but also because the calculation of MNI values relies on detailed stratigraphic understanding (Grayson 1984). As reported in Chapter 3, excavation at Tangarutu proceeded in $10 \mathrm{~cm}$ spits, and while stratigraphic layers were also recorded, the excavators noted complexity that went beyond the three recorded cultural layers (Vogel 2005:24). Given this, it was decided to report the results using the recorded spits rather than layers.

\section{Results}

Forty molluscan taxa were identified, supplemented by crustacean remains in the form of Lepas anatifera plates and abundant crab exoskeleton fragments. These classes of remains will be discussed individually below, together with a discussion of spatial and temporal patterning within the studied sample, insights into local ecology and gathering strategies, and the role of various marine invertebrates within the overall Tangarutu assemblage.

Despite being adjoining squares, there are distinct differences between squares E1 and E2. Firstly, there is a difference in gross sample size, with the E1 total (NISP) for molluscan remains being 1280, and E2 874 (i.e. excluding crab, urchin, barnacle etc, shown in Table 8.1). However, differences in species representation do not simply relate to the effect of variable sample sizes. A number of species are more strongly represented in the smaller E2 sample, including the most common mollusc Nerita morio (E1 n=376; E2 n=398), as well as Clypeomorus batillariaeformis (E1 n=106; E2 n=123), and less common taxa such as Drupa morum (E1 n=0; E2 n=5). There are also species clustered in E1 that are correspondingly underrepresented in E2, including the limpet Cellana tahitensis ${ }^{1}$ (E1 n=169; E2 n=54), polyplacophoran (chiton) plates (E1 n=91; E2 $\mathrm{n}=24)$, and Trochus cf. radiatus $(\mathrm{E} 1 \mathrm{n}=81 ; \mathrm{E} 2 \mathrm{n}=26)$. Taxa represented by 10 or more fragments in E1 and E2 are graphed in figures 8.1 and 8.2 respectively. Table 8.1 shows overall NISP values for all identified marine invertebrate fauna for both squares E1 and E2. 
What these clusters of different taxa appear to represent are episodes of dumping from a specific series of gathering and/or processing events. Figure 8.3 clearly shows that these speciesspecific dumps are not directly correlated with vertical stratigraphy. For example, Nerita morio fragments are entirely restricted to Square A2 in Spit 1, while there are much higher numbers of Clypeomorus batillariaeformis within Square A2 over spits 5, 6 and 7. The complexity of the Tangarutu stratigraphy has been commented on in Chapter 3, and these few examples from the distributions of molluscan taxa amply demonstrate intricate horizontal as well as vertical patterning.

Although the Tangarutu marine invertebrate sample was collected in arbitrary spits rather than stratigraphic layers, considerable vertical patterning is evident. Most obviously, this patterning can be seen in gross overall quantities of molluscan, crustacean and urchin remains. While the pattern is slightly skewed by the conflation of spits $10-13$, it can still be seen that the collection of molluscs dominates over crustacean or urchin exploitation in the lower three spits. Furthermore, this dumping of molluscan remains (see Figure 8.4) is restricted for the

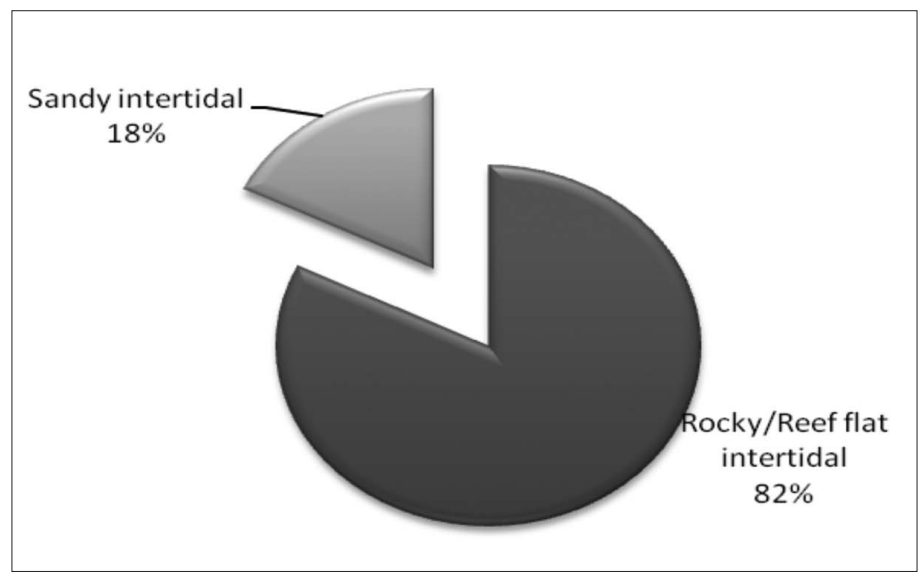

Figure 8.1. Invertebrate taxa represented by 10 or more fragments (NISP) in Square E1, Tangarutu.

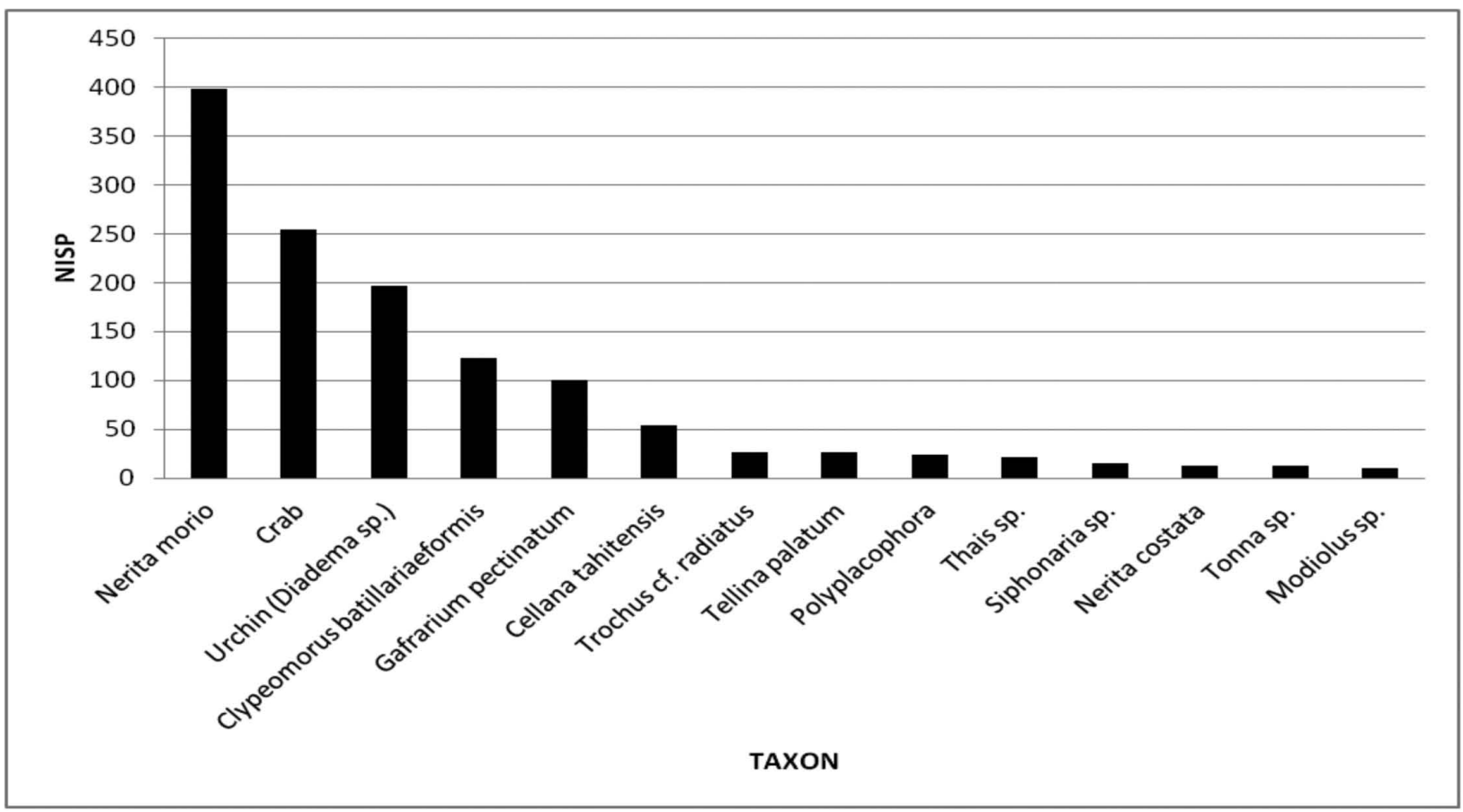

Figure 8.2. Invertebrate taxa represented by 10 or more fragments (NISP) in Square E2, Tangarutu. 
Table 8.1. Invertebrate taxa identified within the E1 and E2 samples from Tangarutu. NISP values given represent the total number of fragments identified for each square. $\wedge$ Indicates absence.

\begin{tabular}{|c|c|c|c|}
\hline Taxon & E1 & E2 & Habitat \\
\hline Crab & 658 & 255 & variable \\
\hline Nerita morio & 376 & 398 & intertidal rocks \\
\hline Urchin (Diadema sp.) & 363 & 197 & inter/sub-tidal \\
\hline Cellana tahitensis & 169 & 54 & intertidal rocks \\
\hline Gafrarium pectinatum & 169 & 100 & sandy intertidal \\
\hline Clypeomorus batillariaeformis & 106 & 123 & intertidal rocks \\
\hline Polyplacophora ("Chiton") & 91 & 24 & intertidal rocks \\
\hline Trochus cf. radiatus & 81 & 26 & intertidal rocks \\
\hline Tellina palatum & 38 & 26 & sandy intertidal \\
\hline Thais sp. & 37 & 21 & intertidal rocks \\
\hline Cypraea caputserpentis & 35 & 7 & intertidal rocks \\
\hline Cypraea spp. & 33 & 4 & variable \\
\hline Modiolus sp. & 21 & 10 & intertidal rocks \\
\hline Nerita spp. Opercula & 18 & 15 & variable \\
\hline Patella flexuosa & 15 & 2 & intertidal rocks \\
\hline Drupa spp. & 15 & 7 & intertidal rocks \\
\hline Lepas anatifera & 13 & 4 & pelagic \\
\hline Chama pacifica & 12 & 1 & inter/sub-tidal rocks \\
\hline Tonna sp. & 10 & 13 & sandy inter/sub-tidal \\
\hline Conus spp. & 9 & $\wedge$ & variable \\
\hline Nerita plicata & 8 & 1 & upper intertidal rocks \\
\hline Drupa ricinus & 5 & $\wedge$ & intertidal rocks \\
\hline Pyrene sp. & 5 & $\wedge$ & intertidal sand/rubble \\
\hline Drupa morum & $\wedge$ & 5 & intertidal rocks \\
\hline Cardita variegata & 4 & 1 & intertidal rocks \\
\hline Tellina scobinata & 3 & $\wedge$ & sandy intertidal \\
\hline Antigona (Periglypta) reticulata & 3 & $\wedge$ & sandy intertidal \\
\hline Drupa rubisidaea & $\wedge$ & 3 & intertidal rocks \\
\hline Astraea rhodostoma & 2 & $\wedge$ & intertidal rocks \\
\hline Phos sp. & 2 & 2 & intertidal rocks \\
\hline Nassarius sp. & 2 & $\wedge$ & variable \\
\hline Pinctada margaritifera & 2 & $\wedge$ & sub-tidal \\
\hline Astraea sp. & 1 & $\wedge$ & intertidal rocks \\
\hline Nerita costata & 1 & 13 & upper intertidal rocks \\
\hline Planaxis sulcatus & 1 & $\wedge$ & upper intertidal rocks \\
\hline Cypraea cribraria & 1 & $\wedge$ & sandy intertidal \\
\hline Strombus sp. & 1 & $\wedge$ & sandy intertidal \\
\hline Siphonaria sp. & 1 & 15 & intertidal rocks \\
\hline Corbula sp. & 1 & $\wedge$ & sandy intertidal \\
\hline Saccostrea cucullata & 1 & $\wedge$ & intertidal rocks \\
\hline Codakia tigerina & 1 & $\wedge$ & sandy intertidal \\
\hline Turbo cinereus & $\wedge$ & 1 & intertidal rocks \\
\hline Hipponix conicus & $\wedge$ & 1 & on other shells \\
\hline Fragum sp. & $\wedge$ & 1 & sandy intertidal \\
\hline TOTAL & 2335 & 1342 & \\
\hline
\end{tabular}




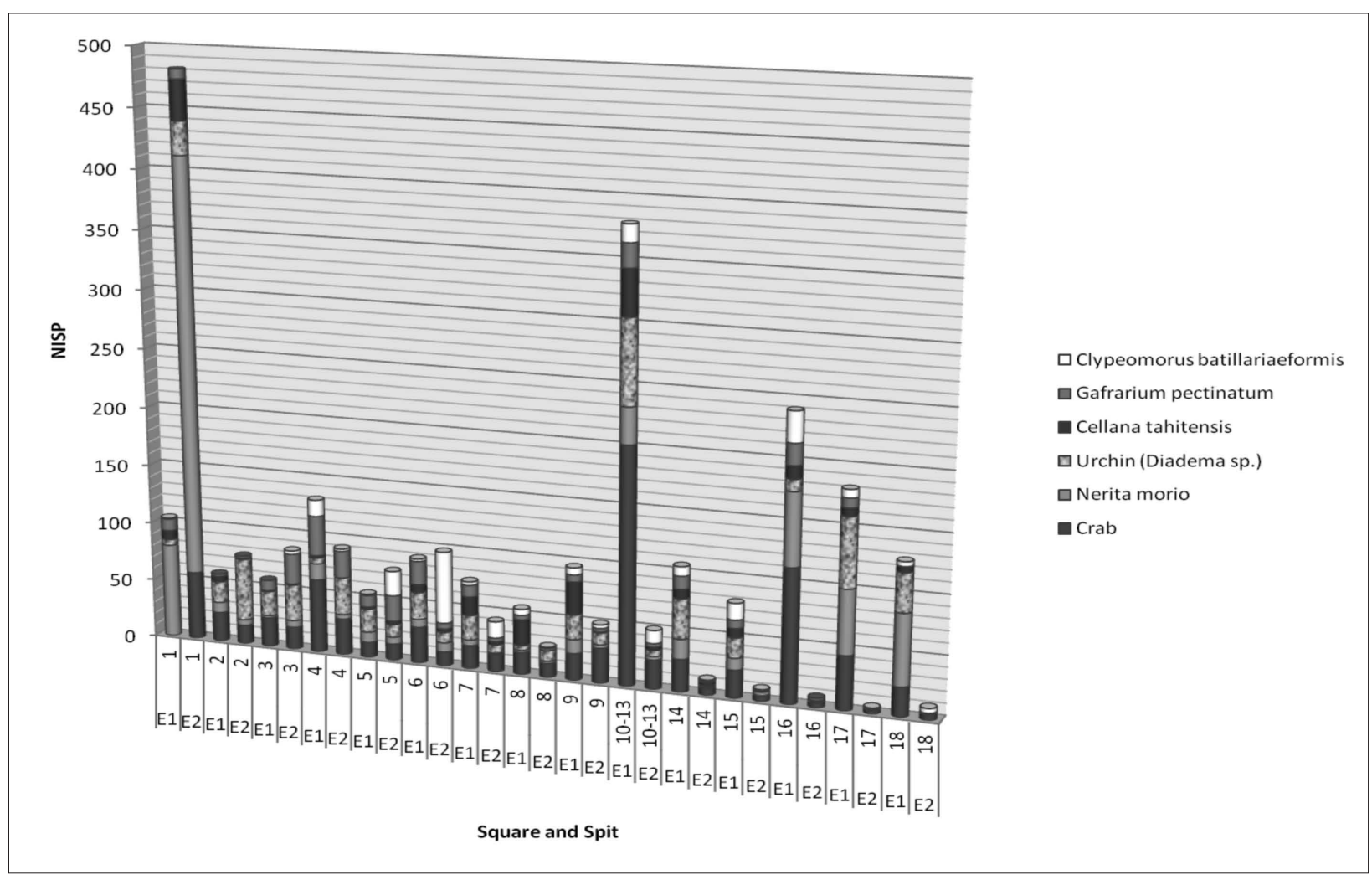

Figure 8.3. The six highest-ranking (NISP) invertebrate taxa graphed by square and spit.

most part to Square E1. Indeed Spit 1 and Spit 6 represent the only two time brackets where molluscan remains are primarily dumped in Square E2. Low levels of Diadema cf. setosum urchin remains are present throughout the sequence, but urchin only predominates over molluscan and crustacean remains in Spit 2, where it is strongly represented in both squares E1 and E2. There are also notable levels of urchin remains in Spit 17, Square E1. Crustacean remains appear in highly variable numbers, but are well represented towards the lower part of the sequence (spits 16 and 17, E1), in the mid-sequence (spits 10-13), and towards the upper part of the sequence (Spit 4 in Square E1 and Spit 1 in Square E2).

Within the molluscan sample, the most obvious stratigraphic difference in species representation can be seen in the large dump of Nerita morio in Spit 1 (largely Square E2) (see Figure 8.3). Nerita morio is present in low levels throughout the sequence, but has a notably strong presence in spits 16-18 (Square E1) at the lowest part of the Tangarutu sequence. Conversely, the soft-shore bivalve Gafrarium pectinatum is represented most strongly in spits 3-6 where representation of Nerita morio is fairly weak. While this could feasibly be construed as a shift away from a focus on the hard shore to the soft shore, the occurrence of other softshore species is scattered and diffuse, with a range of species contributing only a few individuals (e.g. Tellina palatum, Antigona reticulata). As such, any pattern across soft-shore taxa is difficult to pin down (see further discussion in Chapter 9).

Within the hard-shore intertidal category, there is clearly a number of complex relationships between taxa, with both the limpet Cellana tahitensis and the horn shell Clypeomorus batillariaeformis showing different patterns of occurrence to Nerita morio. Although virtually restricted to Square E1, Cellana tahitensis is the dominant mollusc from Spit 7 to Spit 9, with strong occurrences also in spits 10-13. Apart from a small accumulation in Spit 2 (Square E2), Cellana tahitensis numbers are otherwise negligible. The small gastropod Clypeomorus 


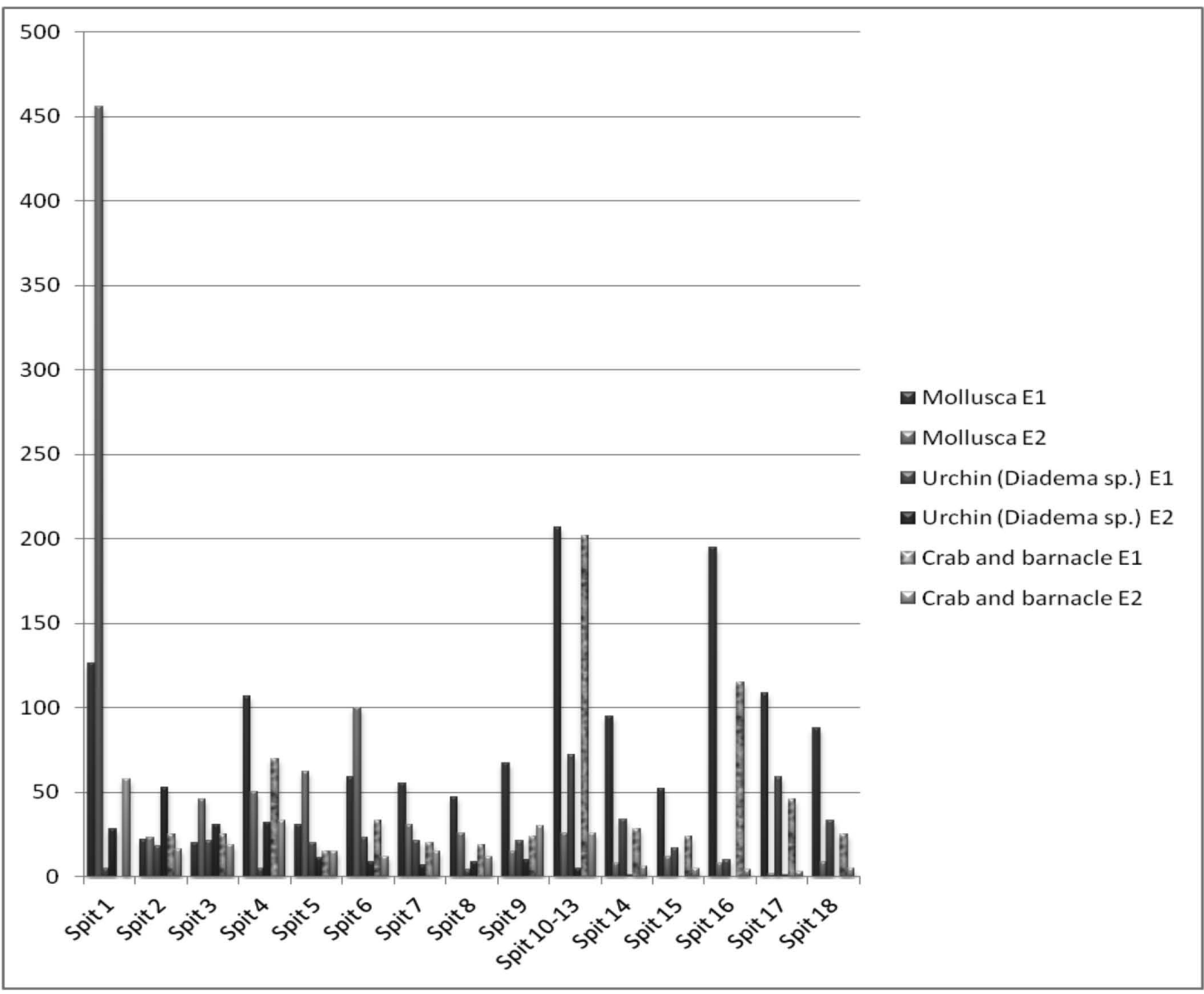

Figure 8.4. Occurrences of molluscan, crustacean and urchin remains throughout the Tangarutu sequence (NISP values).

batillariaeformis has two patches of fairly strong occurrence in the mid-sequence; the first in spits 4-7 (largely in Square E2), and the second lower down, in spits 10-16, oscillating in concentration between squares E1 and E2.

A gross environmental breakdown shows that molluscan taxa derive from two environmental zones: the rocky/reef-flat intertidal niche and the sandy intertidal zone (see figures 8.5 and 8.6). However, the foregoing discussion makes it clear that there are more complex environmental and/or gathering issues at play than simply a focus on either hard- or soft-shore resources.

Nerita morio dominates the Tangarutu molluscan sample as a whole, but as mentioned above, its importance within the overall invertebrate sample fluctuates markedly through time. Nerita morio is one of a group of black nerites that inhabits the temperate and sub-tropical fringes of the Indo-West Pacific, joined by the Australian Nerita atramentosa, the Australian, Lord Howe, Kermadecs, Pitcairn Islands and northern New Zealand Nerita melanotragus, and the Easter Island endemic Nerita lirellata (Spencer et al. 2007). Nerita morio can be found on Easter and Pitcairn islands, as well as the Australs, and is fairly abundant within its restricted geographical range (T. Eichhorst pers. comm.). An algal grazer, it lives under rocks and in tidal pools of the intertidal zone (T. Eichhorst pers. comm.).

Little information is available on the limpet Cellana tahitensis, but it likely shares many features with other species in this wide-ranging genus. Cellana spp. limpets are algal grazers, and nearly all eschew limestone, being found primarily on intertidal basalt surfaces (Preece 1995:346). Clypeomorus batillariaeformis ${ }^{2}$ tends to inhabit the upper mid-littoral zone among 


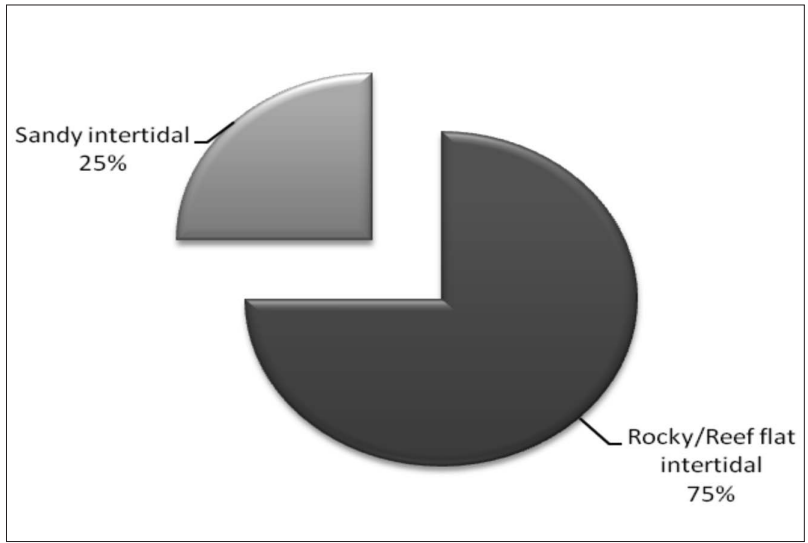

Figure 8.5. Graph to show the broad ecological niches from which the E1 molluscan samples derive.

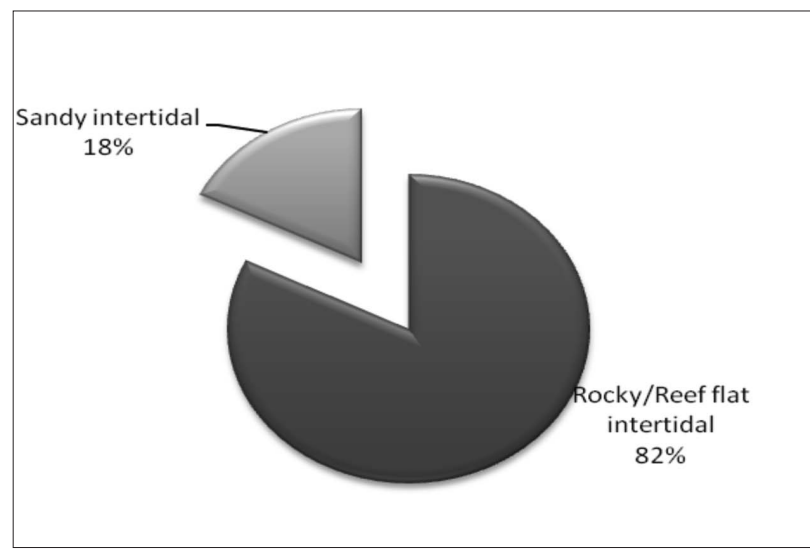

Figure 8.6. Graph to show the broad ecological niches from which the $\mathrm{E} 2$ molluscan samples derive.

rocks or in crevices, being most active during nocturnal low tides (Ayal and Safriel 1983:40). C. batillariaeformis can tolerate some degree of wave action and sand movement (Ayal and Safriel 1983:40), but personal observations of this species on Guam suggest its preference for calmer waters (KS pers. obs. 2007-2008, Tapa'chang Beach, Guam).

The dominance of gastropods over bivalves in the Tangarutu sample is to be expected given the isolation and ecology of Rapa. As Preece (1995:343) points out, insular marine molluscan assemblages tend to be dominated by gastropods, and small islands appear to skew faunal compositions even further in this direction. The presumed reason for this is the frequent paucity of soft littoral substrates on small islands, as opposed the variety of hard-shore habitats that accommodate a diversity of gastropods (Preece 1995:343). Dispersal mechanisms and food availability may also play a part in this (Vermeij in Preece 1995:344).

All urchin remains recovered from the Tangarutu deposits were identified as belonging to the species Diadema cf. setosum. The closely related Diadema savignyi has been identified for Pitcairn Island (Paulay 1989), although greater caution in species attribution for Pitcairn is shown by Irving (1995:314). It is possible that the Tangarutu specimens could belong to either species, or indeed a mix of the two sympatric Diadema taxa. Identification keys are based on discrete colour and anatomical differences (Muthiga 2003), neither of which could be utilised in the analysis of the Tangarutu assemblage.

Diadema spp. urchins have a very fragile test, with long, hollow black spines (Miskelly 2002:22), but one of the most notable features of the Tangarutu Diadema spp. remains is the low numbers of spine and test fragments (Figure 8.4). Instead, urchins were dominantly represented by 'teeth' or other components of the feeding apparatus known as the 'Aristotle's lantern'. This pattern would suggest that primary processing of urchin remains did not happen at the rockshelter itself, but at or near the point of collection. Given the length of Diadema spp. primary spines (up to $30 \mathrm{~cm}$ ), which are capable of causing a painful injury (Miskelly 2002:22), there is good reason to remove the spines before transport. Thus, the Tangarutu urchin remains would indicate that, generally, the flesh and mouthparts alone were transported back to the site.

Diadema setosum is an algal grazer, which prefers a substrate of coarse sand to rubble and little in the way of macrophytes such as Sargassum spp. (Dumas et al. 2007:96). It has been found to avoid finer sediments, such as fine sand or mud, and tends to shun more architecturally intricate substrates such as areas of complex or branching coral cover (Dumas et al. 2007:96). Observations by KS of Diadema setosum in eastern Indonesia (Pulau Kanawa, western Flores), 
suggest that its gregarious nature combined with its occurrence in shallow, coarse sand and rubble areas makes it a highly visible target. Despite its nocturnal feeding patterns, KS has also seen high levels of activity in the late afternoon. The clear abundance of this species in close proximity to the site, coupled with the abundance of algal-grazing molluscs, indicates extensive algal-bearing habitats in Anarua Bay.

A small number of Lepas anatifera barnacle plates were identified within both the E1 and E2 samples. Goose barnacles attach themselves to floating objects such as driftwood by a flexible stalk (Gunson 1983:44; Debelius 2001:310) and, as such, are only found in the intertidal zone or on beaches when washed up with ocean debris. Thus, rather than representing a food source, they indicate the presence of driftwood introduced to the site. While numbers are too small to make any statistically meaningful statements, it is interesting to note that in both squares E1 and E2, occurrences of Lepas anatifera plates stratigraphically match spikes in the abundance of Clypeomorus batillariaeformis. This may indicate periods of slightly greater exposure at Anarua Bay or the introduction of material collected in the winter months.

\section{Tangarutu invertebrate remains in context}

When dealing with a culturally accumulated faunal assemblage, it is difficult to determine whether patterning is due to human agency, the nature of available resources, or a complex mixture of the two. This issue is surely compounded on Rapa, where already sensitive and unstable ecological communities had to incorporate a new member - human colonists. Teasing apart the direct and indirect effects of human intervention in an environment that is apparently so precariously balanced without humans is unlikely to move past reasoned speculation.

That said, arguments for human impact through over-predation have been made for other zones of marginal East Polynesia. Fluctuating frequencies of various molluscan taxa were also detected by Weisler (1995) for Henderson Island in the Pitcairn Group. ${ }^{3}$ At Site HEN-10, Weisler (1995:397, 399) noted that cerithid gastropods (identified mainly as Cerithium tuberculiferum) completely disappear from the record after a period of heavy exploitation. Although Weisler $(1995: 397,399)$ cites this as an example of human over-predation, we would be reluctant to apply such an interpretation to the fluctuating representations of various taxa at Tangarutu, given the ecological complexities.

There can be little doubt that human predation impacted on the local littoral fauna on Rapa, but whether humans directly caused the local extinction or extirpation of particular species at Anarua Bay is more difficult to establish. In addition, while species such as Clypeomorus batillariaeformis are completely absent from the uppermost spits of Tangarutu, other gastropods such as Nassarius sp. and Tonna sp. are completely absent from the lower sections of the stratigraphy. On present evidence, such patterns are just as likely to represent a littoral community in flux as human gathering patterns and/or associated over-predation.

One of the major differences between Weisler's (1995) Henderson Island sites and the Tangarutu sample is the contribution made by urchins and crabs at the latter and their complete absence within the former. Paulay (1989:4) observed in his 1987 survey of Henderson Island invertebrate resources that Diadema sp. urchins occurred 'spine-to-spine'. In his assessment of coral reef biotopes on Henderson Island, Irving (1995:317) cites urchins as 'the most conspicuous invertebrates'. He goes on to state that molluscs and crustaceans were difficult to locate on Henderson's reefs, 'with the presence of many only being revealed by their dry remains on the strandline' (Irving 1995:317). Whether urchins were as abundant around Henderson Island in the past, or whether the archaeological pattern provides evidence of avoidance, is a question that remains unanswered. Urchin exploitation was clearly important to the inhabitants 
of Tangarutu, and although the level of exploitation fluctuated, it was clearly never heavy enough to wipe out local populations. It is more difficult to be categorical about the status of crab, as this category represents a mixture of different species that may show different temporal patterning with further analysis. Nevertheless, it is clear that decapod crustaceans were exploited at steady levels throughout the utilisation of the Tangarutu shelter.

Looking at the overall faunal exploitation patterns in the Henderson Island and Tangarutu assemblages, the differences appear greater than the similarities. Fishing is undoubtedly important in both locales, and it was supplemented by consistent levels of mollusc exploitation. However, there is greater variety of invertebrate exploitation at Tangarutu, with urchins and crabs making a solid contribution to the overall subsistence picture through time. It is possible that this diversification in littoral exploitation on Rapa was a response to the lack of pig and turtle, which evidently were present on Henderson Island. A greater reliance on native resources can also be seen in the use of Aleurites moluccana endocarp and human bone for fishhook manufacture on Rapa (see Chapter 9), while more traditional shell resources were available (or acquired) for fishhook (Pinctada sp.) and adze (Tridacna sp.) manufacture on Henderson Island.

There are obvious difficulties associated with living on small, isolated, impoverished and climatically marginal islands. Given this, it is instructive to note the differences in littoral exploitation patterns between Rapa and Henderson, islands which are so often grouped together for the purposes of ecological discussion (e.g. Paulay 1989:12 and references therein). Both the differences between human subsistence behaviour on the two islands and the fluctuating importance of various marine invertebrate resources within the Tangarutu sample suggest that flexibility and the ability to resource-switch are important factors for survival. Indeed, there can be no 'one-size-fits-all' strategy in a fluid environment. The fact that domesticated animals were not introduced to Rapa in prehistory and the fact that the prehistoric inhabitants of Henderson Island were not capitalising on crustacean and echinoderm resources amply demonstrate that even when resources are scarce, choices exist. A longer-range view of marine invertebrate populations on Rapa, including palaeontological information and modern survey data, may shed more light on fluctuations in community structure and bring into clearer focus the impact of human predation on Rapa's coastal resources.

\section{Notes}

1. Cellana tahitensis is the current valid name for Cellana (=Patella) taitensis more commonly seen in regional literature (OBIS database, record 35389).

2. Ayal and Safriel refer to this species by its junior synonym Clypeomorus moniliferum. Another junior synonym commonly seen in the literature is Clypeomorus moniliferus.

3. It would appear from the molluscan species list that Henderson and Rapa are not directly comparable, with Henderson having some 'classic' Indo-West Pacific taxa such as Turbo spp. and Tridacna sp. which are largely absent from Rapa. The diminutive Turbo cinereus is the only species of Turbo recorded for the Tangarutu sample.

\section{Acknowledgements}

Thank you to Tom Eichhorst for (once again) so generously sharing his vast knowledge of neritids, and to Yolanda Vogel for unpublished information and discussion. 


\section{References}

Ayal, Y. and Safriel, Y.N. 1983. Does a suitable habitat guarantee successful colonisation? Journal of Biogeography 10:37-46.

Debelius, H. 2001. Crustacea Guide of the World. Conchbooks, Hackenheim.

Dharma, B. 2005. Recent and Fossil Indonesian Shells. Conchbooks, Hackenheim.

Dumas, P., Kulbicki, M., Chifflet, S., Fichez, R. and Ferraris, J. 2007. Environmental factors influencing urchin spatial distributions on disturbed coral reefs (New Caledonia, South Pacific). Journal of Experimental Marine Biology and Ecology 344:88-100.

Grayson, D.K. 1984. Quantitative Zooarchaeology - Topics in the analysis of archaeological faunas. Academic Press, Orlando, Fl, and London.

Gunson, D. 1983. Collins Guide to the New Zealand Seashore. Collins, Auckland.

Irving, R.A. 1995. Near-shore bathymetry and reef biotopes of Henderson Island, Pitcairn Group. Biological Journal of the Linnean Society 56:309-324.

Miskelly, A. 2002. Sea Urchins of Australia and the Indo-Pacific. Capricornia Publications, Lindfield, NSW.

Muthiga, N.A. 2003. Coexistence and reproductive isolation of the sympatric echinoids Diadema savignyi Michelin and Diadema setosum (Leske) on Kenyan coral reefs. Marine Biology 143:669677.

OBIS Indo-Pacific Molluscan Database. 2006. Cellana tahitensis species listing. URL: http://clade.ansp. org/obis/search.php/35389 Accessed 14 June 2008.

Paulay, G. 1989. Marine invertebrates of the Pitcairn Islands: species composition and biogeography of corals, molluscs and echinoderms. Atoll Research Bulletin 326:1-28.

Preece, R.C. 1995. The composition and relationships of the marine molluscan fauna of the Pitcairn Islands. Biological Journal of the Linnean Society 56:339-358.

Spencer, H.G., Waters, J.M. and Eichhorst, T.E. 2007. Taxonomy and nomenclature of black nerites (Gastropoda: Neritimorpha: Nerita) from the South Pacific. Invertebrate Systematics 21:229-237.

Vogel, Y. 2005. Ika. Unpublished MA thesis, University of Otago, Dunedin.

Weisler, M.I. 1995. Henderson Island prehistory: colonisation and extinction on a remote Polynesian island. Biological Journal of the Linnean Society 56:377-404. 